\title{
THE TWENTY-FIRST-CENTURY HR ORGANIZATION
}

\section{DAVE ULRICH, JON YOUNGER, AND WAYNE BROCKBANK}

Like any value-creating staff function, HR departments should operate as a business within a business. Others have focused on the strategy and direction of HR departments. This article examines the next evolution for how HR department organization structure can deliver value based on two premises: (1) HR organization should be structurally aligned with the organization structure of the business and (2) because diversified/allied business models prevail, it is important to lay out the five roles and responsibilities of $H R$ that respond to this organization model: service centers, corporate, centers of expertise, embedded HR, and operational HR. The article lays out the duties of each role, the relationship among these roles, and suggestions for implementing this new HR structure. (c) 2008 Wiley Periodicals, Inc.

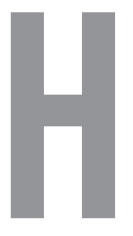

$\mathrm{R}$ departments are increasingly expected to operate as a business within a business rather than as a disconnected and isolated set of HR practices. As such, like any business, HR departments (and other staff groups) must have a vision or strategy that defines where they are headed, a set of goals (objectives, outcomes, or deliverables) that focus the priorities for the work and investments essential to carrying out this vision, and an organization structure that allows HR to accomplish these goals. We have discussed elsewhere that the emerging vision of an HR department is, simply stated, to create value (Ulrich \& Brockbank, 2005) for key stakeholders as follows:
- Employees have the right set of competencies and are committed to the organization and its goals.

- Line managers have increased confidence that business strategies will be executed.

- External customers buy more products or services resulting in greater loyalty and customer share.

- Investor confidence leads to increases in market value through recognition of the company's growth prospects as measured by intangible shareholder value (Ulrich \& Smallwood, 2004).

- Communities in which organizations participate have more confidence in the organization's ability to deliver on its social responsibilities. 
The goals and outcomes of the HR department have also been well documented. The value of HR's contributions has traditionally been measured by the quantity or cost of activities (e.g., how many people were hired in a given time period), the percentage of employees who annually received 40 hours of training, or the financial cost of delivering employee benefits. Instead of focusing on the relatively easy-to-measure activities of staffing, training, or other functional operations, HR departments are better assessed by the outcomes created that support the company's objectives. These outcomes generally may be defined as the
Instead of focusing

on the relatively

easy-to-measure

activities of staffing,

training, or other

functional

operations, $H R$

departments are

better assessed by

the outcomes they

create in support of

the company's

objectives. capabilities an organization requires for its strategy to succeed on a sustained basis (Ulrich \& Smallwood, 2004). For example, organizations may require competitive superiority in speed to market (a consumer products firm bringing new products to market); collaboration (a firm growing through mergers and acquisitions); culture change (a firm trying to shift its firm brand to be more connected with new customer expectations); efficiency (a firm competing on price); service (a firm working to deepen relationships with key customers or grow position in a new customer segment); innovation (a firm competing based on the creation of new products and services); accountability (a firm dedicated to meeting deadlines); or leadership brand (a firm focused on building confidence in the quality of its leaders and leadership as a competitive tool). These and other capabilities represent what the organization is known for, and this identity may be enhanced because the HR practices are aligned with the desired capability. For example, alignment enables an organization's efforts in recruitment, development, communication, compensation, and work design to be more effectively integrated around the capabilities they are trying to deliver. Tracking and measuring an organization's capabilities shift the focus of HR from activities to outcomes. Capabilities become the HR deliverables that show up in employee value propositions, investor intangibles, and firm brand.

With an HR vision of value and outcomes of capabilities, an HR department can now turn its attention to how it can and should be organized to deliver on this vision and reach these outcomes (Christensen, 2005). This article proposes alternatives for how to organize an HR department so that the vision of value and the outcomes of capabilities occur. To create an HR organization, we suggest two basic premises. First, it should be organized to mimic the business organization in which HR operates. Second, since the prevailing business organization for larger, multibusiness, and multigeographic companies is what we term "Allied/Diversified," an HR department operating within this format should reflect this business organization structure by adapting five roles and responsibilities. We conclude with implications for how to manage the transition to implement this next evolution in HR organization.

\section{Premise 1 of the HR Organization: The HR Structure Should Reflect the Business Organization}

As a business within a business, the HR organization should be structured to reflect the structure of the larger business. Business organizations align with the strategies of the business they support, and HR should follow suit. ${ }^{1}$ Companies typically organize along a grid of centralization-decentralization, which leads to three basic ways in which a company operates (see Figure 1): holding company, allied/diversified organization, or single/functional business (Lawler \& Galbraith, 1995).

\section{Single/Functional Business}

When the company is a single business, it competes by gaining leverage and focus. HR's role in the single/functional business is to support that business focus in its people practices. Generally, start-ups and small companies have little or no HR staff. Until a company has 50 to 75 employees, it hardly 


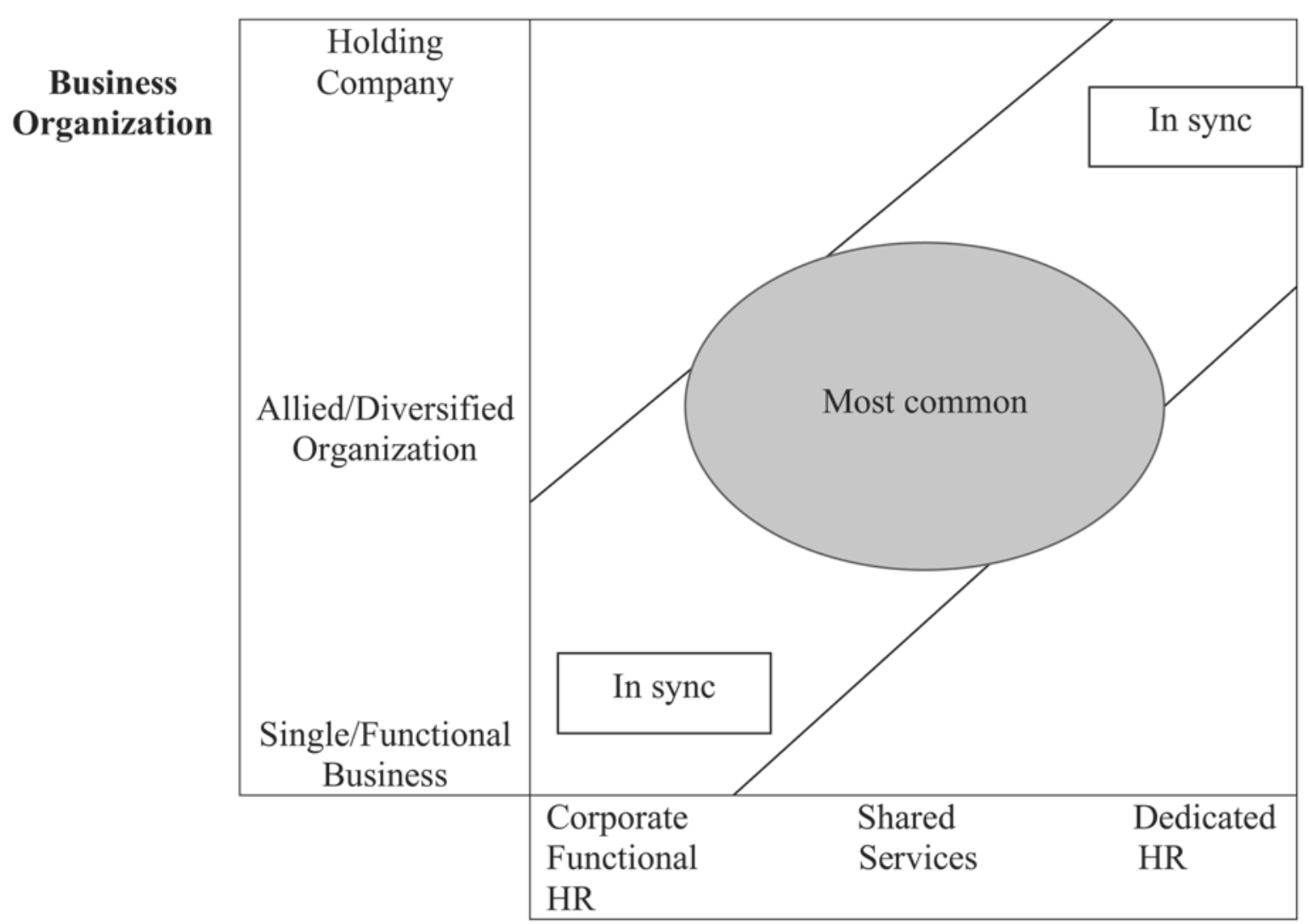

HR Organization

FIGURE 1. Alignment of Business Organization and HR Organization

needs a full-time HR professional; a line manager can usually handle required basic HR activities. As the business grows, so does the HR workload. The business eventually hires someone to oversee HR; set basic policies and practices for hiring, training, and paying employees; and perhaps also run the office and administrative side of the business. This HR generalist will normally be part of the management team and will be consulted on organization needs and changes.

As companies grow, HR departments and staffs grow as well. But as long as the organization remains primarily a single line of business, HR expertise most logically resides at corporate, establishing companywide policies, with HR generalists implementing these policies in the plants or divisions since there is no meaningful differentiation between the business and the corporation.

Herman Miller, for example, was founded in 1923 as a home furniture manu- facturer and branched out into office furniture and ergonomics to become the world's second-largest company in the field (Herman Miller, 2007). It now employs more than 6,000 people worldwide who work in functional departments. Its HR department has corporate specialists in recruitment, development, and compensation who design policies and practices that apply throughout the company. While leadership in defining HR policies comes from corporate specialists, the responsibility for employee engagement rests with line managers, and local HR generalists tailor corporate policies to plant conditions and participate in employee-related decisions.

Herman Miller is by no means the largest company to use this format. McDonald's has more than 13,000 outlets in the United States alone and employs more than half a million people. Most of its employees receive similar treatment because they are in rela- 
tively similar operations. The standardization and integration of services ensure efficiency, low cost, and consistency across the company, while the corporate HR specialists create policies that will work across the McDonald's enterprise to deliver the company's overall strategic agenda.

In a single/functional business organization, a strong HR functional organization usually makes the most sense. This means identifying staff specialists who can design HR practices that match the needs of the business and deliver them to all corners of the company. Employees who move from site to site want to In a single/ find familiar terms and work conditions. Managers want to know functional business what is expected of them regardless of where they work. HR proorganization, a strong HR functional organization usually makes the most sense. fessionals in local plants or operations need a solid line to their HR hierarchy while supporting the business leaders in these local plants or operation.

HR departments in single/ functional business companies are susceptible to the following common mistakes:

- Hyperflexibility. Many HR professionals want their work to be flexible, with unique HR systems and practices for their unit rather than standardized, even though flexibility can do more harm than good when the basic business is similar across the organization. Flexibility in HR should match diversity of business operations.

- Separating corporate and operating-unit HR. As single businesses expand, the increasing workforce seems to generate a need for operating-unit HR specialists. Both corporate and operating units add HR staff, creating a financial and administrative burden and leading to unnecessary proliferation and redundancy of HR practices.

- Isolation. Corporate staff specialists who distance themselves from business realities respond slowly to business changes. Barricaded in corporate offices, they are at risk of designing HR practices that worked in the past but not for the future.

- Disintegration. Functional HR specialists often settle into silos that separate them from one another. When recommendations for new HR policies and/or procedures come from separate specialties, it may become difficult to weave the resulting practices into a unified whole. Too many companies hire based on one set of criteria, train based on a different set, and evaluate performance on yet a third. Then, their leaders wonder why employees lack a common set of goals and objectives.

The HR functional organization suits a single business strategy. It should not be abandoned in favor of the more popular shared service organization unless the structure and strategy of the business mandate the choice. We see only about $10 \%$ of large organizations following this functional organization alignment.

\section{Holding Company}

A company composed of multiple, unrelated, independently managed businesses is best described as a holding company. Pure holding companies are rare (probably about $10 \%$ of overall businesses), although we see some resurgence of holding company structure associated with the rise of large and well-capitalized private equity and investment firms such as Berkshire Hathaway and Blackstone. For example, Berkshire Hathaway owns or controls Dairy Queen, NetJets, GEICO Insurance, and Fruit of the Loom. Blackstone has such varied companies as Celanese, Houghton Mifflin, Southern Cross/NHP, SunGard Systems, TRW Automotive, and Vanguard Health Systems.

In a holding company, there is often little or no HR at a corporate level and little impetus to implement HR. Each business is expected to create and manage its own autonomous HR practices based on the specific needs of the business. Therefore, HR is embedded within the businesses. GEICO, Dairy Queen, and NetJets have HR departments, but Berkshire Hathaway has no cor- 
porate HR. Realistically, as long as the corporation is managed as a group of independent businesses tied together only by a common treasury function (how investment funding is raised) and perhaps investor relations (if the company is publicly traded), HR requirements and the benefits of interaction among subsidiary HR groups are minimal. Even in those cases where there is a corporate HR function, it is likely to be small and focused primarily on executive talent recruiting and managing executive compensation.

While each independent organization may work well, the corporate value is by definition no more (and often less) than the sum of the independent parts. If organizing HR for a holding company, the requirement is to embed dedicated HR departments within business units and ensure they are appropriately focused and well led. Here are some of the common mistakes to avoid:

- Corporate interference. A true holding company should have limited corporate involvement in the HR work done at the business-unit level. Corporate should set general directions and philosophy, but HR policies, practices, and priorities belong to the business units.

- Lack of sharing. Diverse business units find it easy to slide from autonomy into isolation. In the absence of a business imperative for coordination, HR leaders and professionals need to make extra efforts to stay in touch with one another, sharing lessons through learning communities, technology, or other forums. Without a corporate HR function to host and sponsor such meetings, HR departments within independent businesses need to take extra efforts to avoid the "out of sight, out of mind" trap.

- Repatenting the wheel. Even when business-unit HR departments are in touch with one another, they often prefer to develop programs on their own. In the holding company context, the "not invented here" syndrome is especially alive and well, and many professionals are reluctant to utilize programs they did not create. Business HR units in holding companies should consider some form of regular communication that facilitates coordination in areas when unique business solutions are not needed.

- Linearity. We strongly advocate HR focusing on the needs of the business. A danger for HR professionals in holding companies is that they may become overly focused on the short-term needs of the business and may overlook long-term business implications of HR's involvement and potential for contribution. HR must not only focus on those issues central to market share growth and short-term profitability, but must also ensure that the business is operating within a long-term vision and strategy and is complying with regulatory mandates such as affirmative action, disability issues, Sarbanes-Oxley, and labor law.

While relatively few true holding companies exist, the closer a firm comes to that model, the more its HR work needs to be located in dedicated business-unit operations.

\section{Allied/Diversified Businesses}

The choice between functional and dedicated HR is often put as an either/or question: HR exists either at corporate or business-unit levels; is centralized or decentralized; efficient or effective; standardized or flexible. Business units have similar or dissimilar HR practices: the flow of decision making and operational influence is top-down or bottom-up, and so forth. In the kind of reorganization that only looks like progress in aligning the structure with business requirements, companies often shift from one extreme structural configuration to another, not realizing that the key requirement is not the appearance of structural improvement per se but, rather, organizing to reflect the requirements of the business organization. 
Most large companies are not pure and single businesses and do not operate as holding companies. They lie somewhere in between, either in related or unrelated spectra of diversification. They create operating units or business units to compete in different markets yet try to find and exploit the synergies among them. The best of these organizations align their portfolio of businesses around a core set of strategic capabilities that are leveraged across operations. General Electric is an exemplar of the diversified/allied model. For these business organizations, a relatively new way to organize HR resources has emerged called shared services (Bergeron, 2003; Ulrich, 1995). From a dis- tance, shared services looks a lot like centralization, but it is not. Table I points out some of the ways functional HR, shared services, and dedicated HR differ from one another.

Shared services became popular among most staff groups, not just HR, beginning in the late 1990s as a response to general cost pressures. Staff leaders could not simply choose the cheapest and most efficient approach-centralize and standardize all processes-because centralized staff work cannot keep up with the differentiated needs of units within a diversified/allied business. For example, the different businesses within IBM gain leverage from a common approach to talent and performance management, but

\section{T A B L E I Functional HR, Shared Services, and Dedicated HR}

Dimension
Business
organization
Design of HR
policies
Implementation
of HR practices

Functional

- Single business

- Performed by corporate functional specialists

- Governed by corporate specialists

\begin{tabular}{|c|c|}
\hline Accountability & - Corporate HR \\
\hline $\begin{array}{l}\text { Services } \\
\text { orientation }\end{array}$ & $\begin{array}{l}\text { - Standardized services } \\
\text { across the corporation }\end{array}$ \\
\hline Flexibility & $\begin{array}{l}\text { - Mandates use of interna } \\
\text { resources }\end{array}$ \\
\hline Chargebacks & $\begin{array}{l}\text { - Business units pay an } \\
\text { allocation of HR costs }\end{array}$ \\
\hline Location & $\begin{array}{l}\text { Strong corporate } \\
\text { presence with HR } \\
\text { generalists on site }\end{array}$ \\
\hline $\begin{array}{l}\text { Skill } \\
\text { requirements } \\
\text { for HR }\end{array}$ & $\begin{array}{l}\text { - Technically expert in } \\
\text { functional design } \\
\text { and delivery }\end{array}$ \\
\hline $\begin{array}{l}\text { Wealth creation } \\
\text { criteria }\end{array}$ & $\begin{array}{l}\text { - Corporate shareholder } \\
\text { value }\end{array}$ \\
\hline
\end{tabular}

\section{Shared Services}

- Related or unrelated diversification

- Alternatives created by specialists in centers of expertise

- Governed by local HR professionals who select options from center of expertise menu

- Split between operations and HR

- Tailored to business needs with consistency through learning and sharing

- Has flexibility as governed by the centers of expertise

- Business units pay for use of service

- Wherever it makes sense

- Design expertise but also consulting and support

- HR value creation for line managers, employees, customers, and investors

\section{Dedicated}

- Holding company

- Designed and delivered by functional specialists within a business

- Governed by local HR specialists embedded in the business

- Local business leader

- Unique services for each business

- Each business creates what is required

- Business units fund their own HR costs

- Small (or no) corporate HR office, with HR staff at the local business level

- Business expertise and technical specialty in business

- Business-unit growth and profitability 
they require different HR solutions in areas such as compensation where competitive pressures are distinct and different across sectors. Hence, in a number of areas, business consulting-a major and growing commercial focus of IBM-has very different needs from the company's hardware and software divisions, its IT services business, or its R\&D operations. In a world where corporate growth and industry consolidation lead to the increased presence of diversified/allied organization structures, shared services has become a useful means by which organizations balance the efficiencies of centralization with the flexibility required for competing in different markets and/or geographies.

\section{Premise 2 of the HR Organization: To Respond to Prevailing Diversified/Allied Business Models, HR Work Can Be Divided Into Five Roles and Responsibilities}

The HR organization is positioned to create value and deliver strategically relevant organization capabilities when it reflects the structure of the business. This leads to ques- tions about how to specifically organize an HR department to fulfill these needs. Figure 2 shows an overview of the HR organization that facilitates the achievement of these two fundamental ends: value creation and capability enhancement. As the figure illustrates, the evolving HR organization has five distinct and, at times, overlapping roles and responsibilities. These are discussed in the sections that follow.

\section{HR Role and Responsibility 1: Service Centers}

Service centers emerged in the late 1990s as HR leaders (and other functional organizations such as purchasing) realized that many administrative tasks are more efficiently performed in a centralized, standardized way (Reilly, 2000; Ulrich, 1995). The maturation of information technology has also contributed to the growth of service centers and the ability to locate them in lower-cost geographies (e.g., India, Eastern Europe). There is no real limit to centralization. As one HR executive said, "If we move the HR work 400 yards, we might as well move it 3,000 miles." It works

2: Corporate HR:

(top management, integration, corporate initiatives, HR careers)

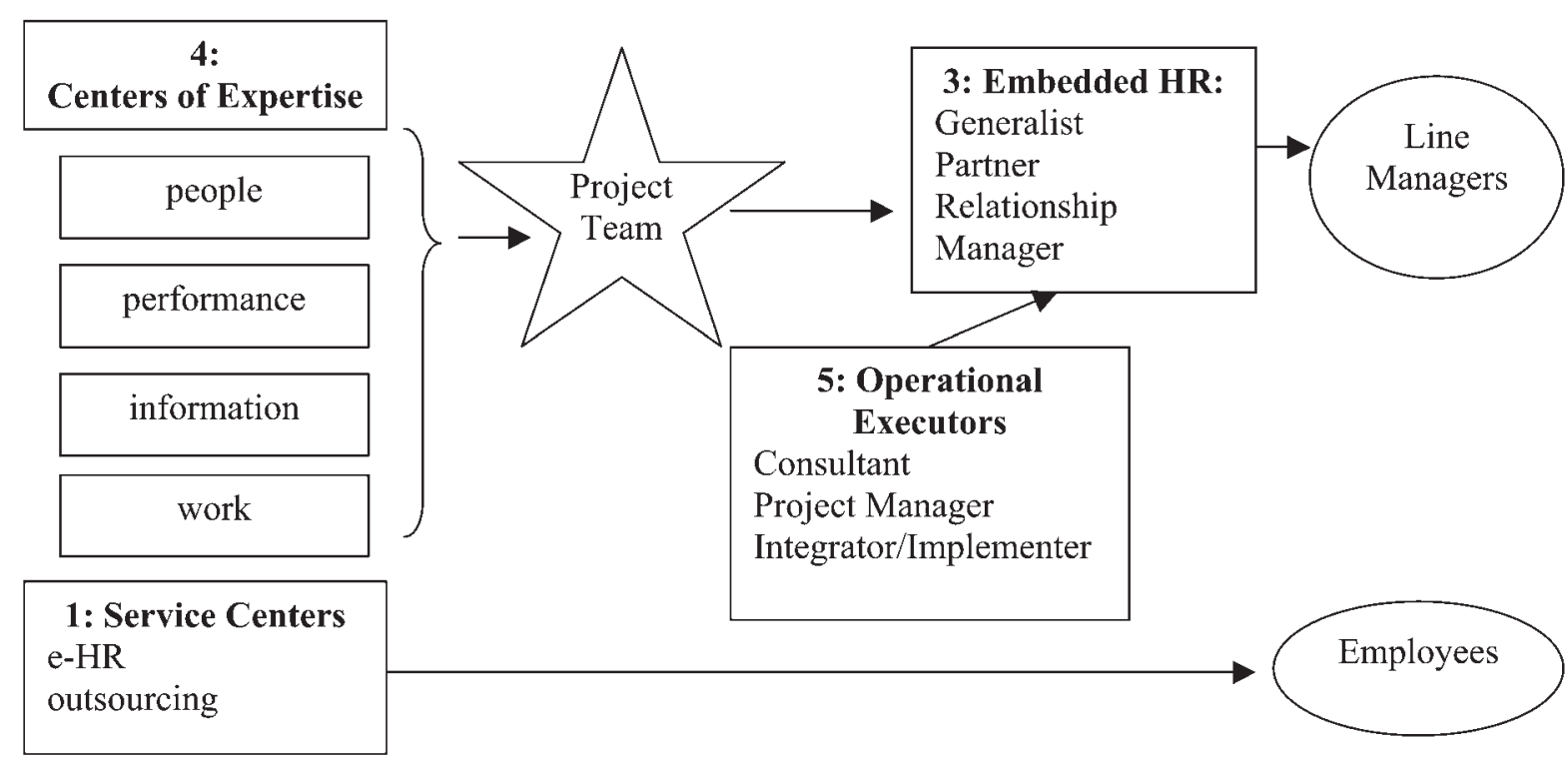

FIGURE 2. Overview of the HR Organization 
because employees are increasingly willing to find answers to routine, standard questions through a service center. Technology enables these centers to access employees and meet basic transactional needs as well or better than other methods.

Service centers enjoy economies of scale, meeting employee needs and resolving concerns by fewer dedicated HR resources. In addition, service centers require a standardization of HR processes, thus reducing redundancy and dupli-

\section{Properly designed}

technology enables

employees to

manage much of

their own $H R$

administrative work. cation. For example, a global oil services firm had more than ten separate ways to register for training; its new service center created a single, standard procedure that increased efficiency and reduced costs. Because of technology, service centers can also be accessible 24 hours a day, 7 days a week, from inside or outside the company. This enhances the service level to employees and retirees.

Service centers offer new ways to do traditional HR work such as employee assistance programs, relocation administration, benefits claims processing, pension plan enrollment and administration, applicant tracking, payroll, and learning administration. Employeerelated transactional processes need to be performed well; performed poorly they have the potential to damage employee morale and destroy HR's reputation. (As one HR executive pointed out, "If we drop the ball on paying people, we will have a very difficult time recovering.") But it is work that we think of as "table stakes," work that must be done to be in the game but certainly not work that is the basis of winning the game. HR organizations are increasingly addressing their transactional needs primarily through technologyenabled employee self-service and through outsourcing. We review the trends and challenges of each in turn.

\section{Service Centers Through Technology- Enabled Employee Self-Service}

Properly designed technology enables employees to manage much of their own HR ad- ministrative work. The popular emerging term for this trend is self-service. They can access HR policy and usage, such as vacation days allotted, and take retirement provisions, such as 401(k) status; career opportunities and qualifications; and their own skill levels (via self-assessment surveys). They can also take care of many routine transactions whenever they wish, because automated systems don't keep office hours. For example, many consulting firms have built their business on HR shared services, designing and delivering an array of HR technologies (Deloitte Consulting, 2006; Mercer Human Resource Consulting, 2008).

We estimate that employees themselves can answer $60 \%$ of their HR questions or transactions (e.g., 401(k) investment choices) online. If they feel uncomfortable with the online service or have an unusual issue, they can contact a service center. Customer service representatives at service centers can usually deal with about $85 \%$ of the remaining queries. A case manager responds to the remaining 15 percent. Some estimates of the cost savings of these tiered solutions are as high as $50 \%$ of HR transaction costs (McRae, 2003).

Relying on technology to perform HR transactions offers a number of benefits. First, it requires standardized HR practices, which avoids duplication, reduces costs, and ensures consistency. Since employees can access HR transactions at their convenience, their perception of service quality also increases. In addition, accuracy improves because employees update and modify their own records. As a result, managers have access to personnel information (such as training and salary history) and are often able to make better decisions about personnel-related matters. As technology-based solutions to routine HR administration increase, a few trends are worth considering-and some emerging pitfalls are well worth avoiding (Lawler, Ulrich, Fitz-Enz, \& Madden, 2003).

- Building from scratch or excessive customization. Companies often regard themselves as unique, but it is best to avoid designing and implementing a 
unique HR data portal and service or to significantly customize one. One company spent thousands of hours creating its unique human resources information technology (HRIT) system only to find that it did not match the capabilities of available marketplace systems. There are many effective HRIT products on the market, and adapting one of them is much simpler and less expensive than building something new or massively customizing a purchased system.

- Believing that channel is content. Occasionally, IT specialists become more enamored with the design and implementation of their technology than with the business success that they should be trying to create. This was a fundamental cause in the dot-com boom and bust of the late 1990s. They fail to remember that information technology is a channel for providing and disseminating information, but the information itself ultimately drives business performance. They need to maintain their business focus and not just their technology focus.

- Forgetting the importance of the employee relationship. The employee's goal for many HR transactions is to finish as quickly and easily as possible. Nonetheless, HR is not like retail banking where customers happily manage transactions by ATM and do not want a personal relationship with the bank. It is more like investment banking where relationships still offer the best long-term approach to customer share. Relationship HR, designed to build loyalty between individual employees and the firm, likewise offers the best long-term approach to employee care.

- Data without insight. One clear benefit of self-service is the ability to collect data on trends and needs. For example, knowing the differences between how many younger and older employees use e-learning can help in planning and employee communication. But data does not improve decision making unless it is used. Data that is warehoused in files and never fully deployed might as well not exist. Good business decisions start with good questions that require managerial insight and foresight; then, data collected through technology-based selfservice can be used to assess alternatives and test hypotheses.

- Intrusiveness. Concerns over privacy continue to be a major challenge. The more data accumulates, the more the firm knows about the employee, and the harder it is to keep the data secure. As useful and convenient as 24/7 access to employee data can be, it blurs the boundaries between work and social life. While each employee needs to find ways to manage this balance, technology may become increasingly intrusive and inhibit work-life balance that helps to give employees purpose and meaning at work and at home.

Even with these concerns and challenges, technology will increasingly be used to facilitate employee transactions. As the technology becomes more userfriendly and accessible, it will help employees manage their personal careers and will help leaders use employee data and resources to produce value for the company.
As the technology
becomes more user-
friendly and
accessible, it will
help employees
manage their
personal careers
and leaders use
employee data and
resources to
produce value for
the company.

\section{Service Centers Through Outsourcing}

As we pointed out earlier, organizations are taking two distinct approaches to dealing with routine transactional HR tasks. The preceding section describes how organizations insource HR transactions through technology-enabled self-service. Other firms use outsourcing.

Outsourcing draws on the premise that knowledge is an asset that may be accessed without ownership. HR expertise can be shared across boundaries by alliances in which two or more firms create a common service or by outright purchase from vendors 
who specialize in offering services (Cook, 1999; Scott-Jackson, Newham, \& Gurney, 2005).

Vendors take advantage of economies of knowledge and scale. Economy of knowledge allows them to keep up with the latest research on HR issues and with the latest technology to offer transaction support that accesses the most recent ideas and is delivered in the most efficient way. Economies of scale make it possible to invest in facilities and technologies beyond what is realistic for a single company. Firms such as
Companies using Hewitt, Accenture, and Towers Perrin are therefore able to offer HR outsourcing increasingly seek integrated solutions rather than isolated practices. bundles of HR services with the goal of moving client companies away from the traditional idea of outsourcing to multiple vendors-one for staffing, another for training, another for compensation, and so on-all taking somewhat different approaches to their work.

Companies using HR outsourcing increasingly seek integrated solutions rather than isolated practices. For example, HR systems can identify the skills required in hiring for certain jobs and then use these skills to source and screen talent. When considered as an integrated solution, the skill requirements can also be applied to training, compensation, and job assignments. Integrated solutions require vendors with expertise in multiple HR practice areas. BP, Prudential, Bank of America, and others have pioneered the outsourcing of HR transactions (Lawler et al., 2003). Though outsourcing on this scale is too new for results to be definitive, these firms have experienced several potential benefits of outsourcing:

- Cost savings. Savings have been in the 20 to $25 \%$ range-a substantial amount for large companies, which spend an average of $\$ 1,600$ per employee, per year on administration. Firms with 10,000 employees, for example, could estimate saving $\$ 3,200,000$ per year $(20 \%$ of $\$ 1,600$ per employee $\times 10,000 \mathrm{em}$ ployees).

- Standardization. Outsourcing requires consistent HR transactions. Many large firms have grown through mergers and acquisitions, accumulating diverse HR systems. Simply contracting out this work forces a level of consistency that might have taken years to accomplish internally.

- Increased speed and quality of service. As we mentioned, outsourcing vendors generally rely on technology and have the economies of scale to stay up to date with new developments that continuously improve their services. Employees often perceive service as actually improving with effective outsourcing.

- HR focus. Outsourcing enables HR professionals to focus on more strategic work. Thus, outsourcing increases the likelihood that HR professionals will become more strategic in thought and action.

These benefits need to be analyzed over a longer period to assure the value of outsourcing. Nonetheless, while early indicators suggest that outsourcing offers positive returns, exist risks and pitfalls as well:

- Picking the wrong vendor. As with any new business, not everyone who offers the service is really able to deliver excellent work, keep up with the volume, and ensure continuity of service. However, it seems likely that increasing competition will winnow vendors to those who can meet these criteria.

- Unbalanced contracts. The contract between the outsourcing provider and the organization may be skewed toward one party or the other, and contractual terms may make dispute resolution difficult. It is essential to specify current and desired service levels in mutually agreeable terms, outline a procedure for dispute resolution that both parties find fair and equitable, and include incentives for performance for the vendor and cooperation for the company. 
- Lack of change management. The changeover from internal to external vendors is often difficult, time-consuming, prone to early errors, and therefore upsetting to employees, line managers, and HR professionals. While some confusion is inevitable, change processes that plan for alternative scenarios, engage employees and other affected parties in the process, and learn from self-correcting systems are important in increasing the probability of successful change.

- Sprawling efficiency. Outsourcing firms that want to expand their revenues sometimes do so by convincing a line manager who has an antiquated view of HR that the outsourcing firm should take over all of the HR functions and design and implement them against the primary criterion of transactional efficiency instead of business sensitivity. Such thinking moves HR back a generation when we saw ourselves as a cost to be reduced instead of partners who drive the business. Internal HR professionals should be on guard for this tendency among some HR outsourcing firms.

- HR role conflict. Outsourcing changes HR's role in the company. Employees who used to know who to see and how to get things done now have to rewire their expectations and work norms. HR professionals who developed an identity and reputation based on effectively serving the transactional needs of employees and managers now need to reorient themselves to higher value-added activities and agendas.

- Loss of control. The firm surrenders control of outsourced transactions-but the need for the transactions will not diminish. If outsourcing vendors have business problems, they will dramatically affect the firm's ability to relate to its employees.

Despite these risks, we believe large firms will continue to outsource bundles of HR transactions to increasingly viable vendors. Smaller firms will probably outsource discrete HR practices such as payroll and bene- fits administration. Both types of outsourcing reflect the collaborative work across boundaries that will characterize the organizations of the future.

\section{HR Role and Responsibility 2: Corporate HR}

HR professionals who perform corporate HR roles address six important areas of need within the emerging HR organization, which are discussed in the sections that follow:

- They create a consistent firmwide culture face and identity.

- They shape the programs that implement the CEO's agenda.

- They ensure that all HR work done within the corporation is aligned to business goals.

- They arbitrate disputes between centers of expertise and embedded HR.

- They take primary responsibility for nurturing corporatelevel employees.

- They ensure HR professional development.

Such thinking moves

HR back a

generation when we

saw ourselves as a cost to be reduced

First, corporate HR professionals create a consistent cultural face and identity for the corporation. No matter how diversified the business strategy, a variety of important external stakeholders form broad relationships with the entire firm. Shareholders tend to care mainly about overall performance, and large customers who do considerable business with the firm tend to engage with many different divisions. Likewise, the image of the entire firm is often what attracts potential employees to specific divisions. Corporate HR professionals build the firm's culture and reputation by focusing on values and principles. Hewlett-Packard (HP), for example, has diversified dramatically, but the guidance of the HP Way continues. A similar thing could be said for Johnson \& Johnson and its credo of business values, or Takeda Pharmaceutical Company and its philosophy of Takeda-ism. 
Line managers own the principles, but corporate HR architects institutionalize them. It takes more than publishing a set of values to make them real. They have to be a guiding factor used and reinforced consistently in interactions with shareholders, suppliers, customers, and employees.

Second, corporate HR professionals shape the programs that implement the CEO's agenda. Most CEOs have a corporate strategic agenda-for example, globalization, product innovation, customer service, or social responsibility. Corporate HR professionals are expected to convert this agenda into a plan for investment and action and build organizational readiness to deliver this agenda through a three-step process:

1. Determine what capabilities are required to deliver the strategy.

2. Choose HR practices from the flows of people, performance management, information, and work that would best deliver those capabilities.

3. Build an action plan for designing and delivering those HR practices throughout the organization.

...corporate HR has

responsibility to

make sure that all

HR work done

within the

corporation is

aligned with

business goals.
This action plan does not involve corporate HR in doing all the work or even in refining all the details. Instead, it will call on centers of expertise to create menus of specific choices, embedded HR professionals to appropriately tailor solutions to each business, and line managers to accomplish strategic goals through the HR service. However, corporate HR ensures that the work is done well and coordinated effectively to achieve the goals.

Third, corporate HR has responsibility to make sure that all HR work done within the corporation is aligned with business goals. This means that corporate HR should not mandate business-unit initiatives since they probably do not understand the business-unit realities as well as the embedded HR professionals. But they should mandate a clear and definitive linkage between business strategy and HR within the business units. One metaphor we have found helpful is to describe corporate HR as playing the role of devil's advocate for strategic $H R$, challenging the need for both sameness and difference in HR practices across operations and specific businesses. In addition, corporate HR should ensure that business-unit HR is involved in setting measurable objectives. They should also be actively involved in facilitating the measurement process to eliminate the conflict-of-interest problems that would occur in business-unit HR doing its own measurements.

Fourth, corporate HR professionals arbitrate disputes between centers of expertise and embedded HR (HR professionals within the businesses or operations). The former naturally lean toward consistency; the latter prefer flexibility and choice. Corporate HR will not have a magic answer or uniform formula for deciding when to standardize practices and when to vary them, but it can focus on value creation for multiple stakeholders and shift HR practices to create that value in each specific instance. We call this managing the push (centers of expertise) and pull (embedded HR) that requires conversation and, at times, arbitration.

Fifth, corporate HR professionals take primary responsibility for nurturing corporatelevel employees-a role both like and unlike that found elsewhere in the firm. Like all employees, corporate employees should perform their transaction HR work through service centers or technology. However, some corporate employees are unique in that their relationship with the firm is visible and symbolic. Public reports of executive compensation, for example, require extra care to ensure the right messages are communicated to all internal and external stakeholders. Senior HR professionals also frequently play significant roles in coaching senior executives, offering advice ranging from personal leadership style to dealing with key employee transitions and succession issues to observations and assistance in evolving the corporate culture.

Finally, corporate HR is responsible for HR professional development. Too often, HR 
professionals are the cobbler's barefoot children-designing learning experiences for others, for example, while going without a similar investment in their own development. HR corporate staff should help HR professionals grow, unlearn their old roles, and learn new ones. This may require hiring a new type of HR professional with new knowledge, skills, agendas, and aspirations. This may require moving established HR professionals to different roles and increasing investment in HR development and training.

\section{HR Role and Responsibility 3: Embedded HR}

In shared service organizations, some HR professionals work in organization units defined by geography, product line, or functions such as research and development or engineering. These HR professionals, whom we call "embedded HR," go by many titles: relationship managers, HR business partners, or HR generalists. Whatever their specific title, they work directly with line managers and each organizational unit leadership team to clarify strategy, perform organization audits, manage talent and organization, deliver supportive HR strategies, and lead their HR function (Brown et al., 2004). Embedded HR professionals play a number of important roles that include the following:

- They engage in and support business strategy discussion.

- They represent employee interests and implications of change.

- They define requirements to reach business goals and identify where problems may exist.

- They select and implement the HR practices that are most appropriate to the delivery of the business strategy.

- They measure and track performance to see whether the HR investments made by the business deliver the intended value.

In the first role, embedded HR professionals engage in and support business strategy discussions, offering insights and helping leaders to identify where their organization can and should invest resources to win new business ventures or increase existing investments' performance. They should help to frame the process of business strategy development, should be proactive in providing insights into business issues, and should facilitate effective strategy development discussions within the management team. From the results of the most recent HR competency survey, this role reflects a competency we have elsewhere called the "strategic architect" (Ulrich, Brockbank, Johnson, \& Younger, 2007).

In supporting strategic decision making, HR professionals also represent employee interests and highlight implications that follow from the inevitable changes or developments as a result of strategy decisions and changes. For example, how much of the workforce needs to be retrained, reorganized, or resized? HR professionals help develop a clear strategic message that can be communicated to employees and translated into action. In the process, they watch out for the tendency to groupthink, encouraging everyone to participate and clearly valuing dissent while seeking consensus (Chartered Institute of Personnel and Development [CIPD], 2005).

As strategies are being set, and once they are established, embedded HR professionals are to audit the organization to define what is required to reach the goals and where problems may exist. Sometimes this is an informal process whereby HR professionals reflect on and raise concerns about strategy delivery. Other audits may involve a formal $360^{\circ}$ to determine what capabilities are required and available given the strategy (Ulrich \& Smallwood, 2004). These audits will help to identify if the corporate culture on the inside is consistent with the culture required to make customers happy on the outside. In 
doing these organization audits, embedded HR professionals partner with line managers and collect data that lead to focused action.

Based on organization audit information, embedded HR professionals select and implement the HR practices most appropriate to delivering business strategy. In doing so, they are expected to bring their unique knowledge of the business and its people in selecting practices that add value, integrating them to deliver capabilities, and sequencing them to ensure implementation. Embedded HR professionals acquire guidance and support from HR specialists who reside in centers of expertise and adapt both to the requireAs internal design ments of the business. This process of accessing rather than owning resources means that embedded HR professionals must be adept at influencing and working collaboratively with colleagues, because centers of expertise have corporate agendas. They must be effective at managing temporary teams, and often multiple teams.

Finally, embedded HR professionals measure and track performance to see whether the HR investments made by the business deliver their intended value. In essence, embedded HR professionals diagnose what needs to be done; broker resources to get these things done; and monitor progress to ensure things are accomplished.

\section{HR Role and Responsibility 4: Centers of Expertise}

Centers of expertise operate as specialized consulting firms inside the organization. Depending on the size of the enterprise, they may be corporatewide or regional (e.g., Europe) or country-based (e.g., Germany). They often act like businesses that have multiple clients (business units) using their services. In some cases, a fee for use or a "chargeback" formula plus an overhead charge for basic services may fund them. The financing of centers of expertise is sometimes set to recover costs and, in other cases, is comparable to market pricing. Typically, businessesthrough their embedded HR units-are directed to go to the center before contracting for independent work from external vendors. If, in working with the center experts, the business decides to go to outside vendors, the new knowledge the vendors provide is then added to the current menu for use throughout the enterprise. Centers are demand-pull operations-if businesses do not value their services, they will not continue. Center of expertise HR professionals play a number of important roles:

- They create service menus aligned with the capabilities driving business strategy.

- They diagnose needs and recommend services most appropriate to the situation.

- They collaborate with embedded HR professionals in selecting and implementing the right services.

- They create new menu offerings if the current offerings are insufficient.

- They manage the menu.

- They shepherd the learning community within the organization.

As internal design and process consultants, HR professionals in centers of expertise create menus of what can be done that are aligned with the capabilities driving business strategy. The menus are finite. Embedded HR professionals are expected to choose from these menus, which legitimizes the HR practices in use companywide. Process experts consult with embedded HR to help pick the options that best solve specific business problems.

This also points out the second role of the center of expertise HR professional-to work with embedded HR professionals to select the right practice or intervention for a particular situation. For example, say an embedded HR generalist realizes the need for a first-line supervisory training program in his/her organization. The center of expertise should already have a menu of choices, perhaps including an in-house 
workshop, relationships with externally provided workshops (through consultants or a local university), a video program, a self-paced computer learning exercise, a $360^{\circ}$ feedback exercise, and other development experiences. If a current menu doesn't exist, the design experts will assemble one based on their knowledge of the field and the company. A process expert takes this menu to the embedded HR professional and helps him or her diagnose the need and select the services most appropriate for the business and situation, offering advice on how to implement the selected choices.

The embedded HR professional is responsible for the selecting and implementing the right development experiences to improve first-line supervision. However, as a third important role, the center is expected to collaborate in making the selection and in supporting the implementation.

If the embedded HR and center expert agree that existing menu items are not sufficient, the design experts create new solutions that will then be added to the menu for the enterprise. Hence, the fourth role is the creation of new offerings when the current slate is insufficient or inadequate for the need. In many cases, the need for additional menu offerings will be prompted by a company acquisition or decision to diversify and invest in new businesses. For example, we earlier mentioned the growth of IBM into global consulting services. As the organization shifted from products to services, new HR offerings were established to respond to the need.

This points out the next role of the center of expertise-to manage the size and breadth of the process or service menu. In general, the size of the menus will depend on the degree of business diversification. In related diversification, the menus will be smaller, ensuring that different businesses use similar management practices; in unrelated diversification, the menus will be larger, allowing more flexibility. In all cases, there is an important need for the center of expertise to manage the boundaries of what is helpful, acceptable, and permitted. As a very simple example, a large regional bank conducted an audit of its training practices and discovered that 12 distinct and different coaching programs were used in various parts of the organization. The center of expertise reduced that number from 12 to one, with both a cost benefit to the organization (better contracting) and the creation of a common language and skill base in coaching.

Finally, centers of expertise also shepherd the learning community within the enterprise. They initiate learning when design experts generate new ideas for the menu; then, process experts generalize learning by sharing experiences across units. For example, they share the experiences of supervisory training from one unit to another so that each business does not have to recreate its own training programs. The process experts may transfer the learning, or they may have the requesting organization unit communicate directly with those who have previously done the work.

Centers of expertise provide a number of very important benefits to the HR organization and can be found in many companies. However, they also create a number of risks that the HR leadership teams need to manage:
If center experts

isolate themselves

from day-to-day

business problems,

their menus are apt

to offer solutions

that are

academically

rigorous but

irrelevant to

business needs.
- $\quad$ One size fits all. Center experts

tend to fall into routines and push programs that are familiar to them; left to themselves, they may fail to adapt their programs to the needs of each business. It takes careful attention to the needs of the business and to state-of-the-art HR practices in order to ensure that menus continue to evolve.

- Out of touch with reality. If center experts isolate themselves from day-to-day business problems, their menus are apt to offer solutions that are academically rigorous but irrelevant to business needs. HR functional experts must bridge future ideas to present problems. They need to 
turn theory and best practice into effective action. The centers need to bring more than a fixed menu. They need expertise, knowledge base, and foresight to address specific issues (i.e., loss of talent in quickly and unpredictably developing markets such as China and India, for instance). Their work and contribution have to be differentiated enough from the normal solution so that the "We have already done this. What else can you bring?" syndrome does not emerge.

- Canned solutions. It is much easier to have a solution in search of a problem than to design a solution for a problem. Like independent con-

Embedded $H R$ sultants, center experts are often tempted to craft single solutions that they sell to multiple businesses. This is particularly true when centers service global operations. Tailoring solutions to diverse global markets requires agility and thoughtfulness.

- Not invented here. Embedded HR professionals who worry more about personal credibility than impact may be reluctant to use the best practices proposed by center experts. If either center experts or embedded HR professionals declare themselves more important to the business and are, therefore, now willing to learn from each other, then the entire process falters.

- Unquestioned authority. When business units are required to use the center, the experts there find it easy to assume the units are happy to do so. They need to monitor their customer service scores as measured by embedded HR professionals and pay attention to the response.

- Excess demand. Given that centers serve multiple businesses, demand can easily exceed capacity, leaving neglected businesses to flounder on their own or reinvent the wheel on the fly.

- Seduction of power. In some HR functions, centers of expertise have had a tendency to become a law unto themselves. That is, instead of framing their role as consultants whose role it is to help embedded HR drive business-unit agendas, they may be inclined to arrive in the business units brandishing corporate authority and the intent to drive their functional agenda instead of the business units' needs.

While none of these risks is insurmountable, they indicate that centers will inevitably evolve as they refine their approach to delivering HR resources.

\section{HR Role and Responsibility 5: Operational Executors}

A large number of HR departments have attempted to operationalize the above model with shared services (service centers and centers of expertise) and embedded HR. But many of these departments are finding that some work continues to fall through the cracks (Reilly \& Williams, 2006). In research on the HR organization, Reilly, Tamkin, and Broughton (2007), under the auspices of the CIPD, surveyed 800 senior HR professionals about their experience with their HR organization. Among their findings were:

The survey results bear out that introducing shared services has produced boundary problems (identified by $55 \%$ of respondents), gaps in service provision $(42 \%)$ and communication difficulties (37\%). Communication with the rest of the function was a key problem with centres of expertise (34\%) and the difficulty of separating out transactional work $(45 \%)$ was even more of an issue. Similarly, "getting drawn into the "wrong' activities" was the number one problem with business partners.

While embedded HR professionals are asked and expected to be strategic and conduct organization diagnosis, they often find themselves overwhelmed by operational HR work that conflicts with their main purpose. This renders them unable to make time to be strategic. They report that they spend a growing amount of time doing individual 
casework (e.g., handling disciplinary issues), performing operational tasks (e.g., setting up and attending recruiting interviews), doing analysis and reporting (e.g., managing compensation reviews), delivering initiatives (e.g., creating development experiences), or implementing business initiatives (e.g., doing the analysis and execution for a new organization structure). For example, Laurene Bentel (personal communication, November 12, 2007), the VP of HR at Takeda Pharmaceuticals North America points out, "The operational demands on our HR generalists make it extremely hard for them to remain focused on their strategic agenda."

Service centers typically do not perform these operational tasks because they require personal attention; centers of expertise do not do them because they usually require deep and unique knowledge of the business and strong internal business relationships. Line managers do not do them because they lack the technical expertise. Hence, embedded HR professionals feel drawn into this operational work by the volume of it, even when they have the skills and self-confidence to be more strategic and are encouraged to focus on their transformational role.

A second driver is the velocity of program change emanating from corporate HR or centers of expertise. Particularly in times of corporate change and transformation, embedded HR professionals are expected to keep up with a wide number of corporate initiatives-from new measures and measurement to required corporate training and communication programs to new modifications to the performance management and development system. As a result, many embedded HR people are encouraged to do strategy by their line management but required to do implementation by corporate HR. Some HR executives might be led to say, "We are asked to be business partners and strategists, but we end up acting as "pairs of hands' for corporate HR."

It is also the case that often these embedded HR professionals come from an implementation background and lack the skill or self-confidence (or both) to comfortably function at a more strategic level. For these individuals, the urgency (and comfort) of immediate operational requirements outweigh the importance (and developmental interest) of the more strategic future. Too often HR professionals in centers of expertise offer insight and menus of choice, but they do not facilitate or partner in the operational implementation of these ideas. Service centers deal with administrative challenges, but they, too, do not deal with implementation of new administrative systems and practices at the business level.

What has been missing in some HR restructurings is the capacity to deliver and implement the ideas from the center, while maintaining focus on the business and its customers. While this work ideally occurs through an integrated team (see Figure 2), someone needs to be charged with this team and how it works. We are finding that companies are responding to these missing implementation requirements in different ways:

- One company established the role of junior business partners to be assigned to the HR generalists or business partners. These individuals would be required to turn the strateWhat has been missing in some $H R$ restructurings is the capacity to deliver

and implement the

ideas from the center, while maintaining focus on the business and its customers. gic ideas into operational practice within the business.

- Another company created a team of HR operational consultants who were assigned to a business to help turn the strategy into action. They were focused on project work with an emphasis on implementing specific projects within the business. The consulting pool had HR professionals who were gifted at making HR initiatives happen, and it secondarily served as a preparatory and testing ground for individuals slated as potential incumbents for senior embedded HR professional roles.

- Another company uses a case advisor who comes from the service center to follow through on employee requests. 
The Kellogg Company offers an interesting example. As Kellogg transforms into a truly global foods company, there is a greater need for common practice in how people are developed for succession management and for the development of leadership competencies. Thus, the centers of excellence deliver a steady flow of innovative HR practices with the expectation that embedded HR groups within business units will implement them. But embedded groups are already extremely busy

Each of these

companies, and

many others, are

experimenting with managing the strategic and dayto-day requirements of their business units. Tensions have inevitably arisen. At a recent offsite with the HR leadership team, Kellogg began to think through how it might establish an operations HR unit that would provide suphow to solve this common problem: how to make sure that HR implements port to both the centers of expertise and to embedded HR units.

National City, a large regional bank headquartered in Cleveland, Ohio, faced a similar challenge and has been a pioneer in the development of operational HR. Its solution was to create a fifth leg called the HR consulting pool. The consulting pool operates as a team of high-performing midlevel HR professionals and is managed as a cohesive unit. The unit reports to the head of regional (e.g., embedded) HR. Team members are deployed to assist joint center and embedded HR teams to implement solutions to important HR projects-for example, to develop and implement a strategy to reduce attrition in call centers run by the consumer bank. Historically, center and embedded HR professionals would have worked together to scope the need but would not have had the resources to actually implement. Inevitably, the problem-while well defined-would not be effectively addressed and would often be delegated to line management, the worst possible outcome. The operational HR pool solves this problem and has been responsible for a number of important deliverables.
Each of these companies, and many others, are experimenting with how to solve this common problem: how to make sure that HR implements state-of-the-art strategies tailored to the needs of the business. We call this an operational executor role. These HR professionals will be required to meld what the business requires for success (driven by the embedded HR professionals) with innovative and state-of-the-art HR practices (driven by the centers of expertise) into an operational plan that can be executed in a timely way.

There are some identifiable challenges for organizations thinking of creating an operational HR capability that need to be addressed to be successful. Our discussions with HR leaders suggest the following factors are particularly important.

\section{Selecting the Right Individuals}

Operational HR roles require a particular set of competencies. These roles are best for people who are execution- and implementationoriented rather than focused on strategic relationships (embedded HR) or new knowledge creation (centers of expertise). However, operational HR roles can also be excellent developmental opportunities for both embedded and center professionals. In fact, HR departments with companies such as Kellogg and National City consider success in an operational HR role a necessary step in qualifying for a more strategic role. We think that, over time, HR organizations will find that operational HR is best considered a mix of longtimers (people who like to do this work) and rotational resources. The following indicates the skill sets that will be required of HR professionals in operational roles.

- Applying project management skills. Project and implementation management skills are crucial for operational HR professionals. They will need team skills to bring together the relevant players to create operational results. They must quickly understand what is expected; bring together the embedded, business, and center HR professionals in clarifying goals, roles, specific actions, and measures; and make the 
changes happen. Some diagnostic skills are also important; the structure of a project plan must, for example, be cognizant of situational (and often political) dynamics, and mindful of other competing activities. Operational HR resources should not be seen as simply pairs of hands to implement but rather as involved early in the development of solutions.

- Managing priorities and workloads. Choosing what projects are appropriate for operational $\mathrm{HR}$ is an important process task. HR doesn't have infinite resources, and it could be easy for HR to use its precious operational resources on lower-priority work that other HR professionals do not want to do. This would be a mistake and would both trivialize the operational HR work and operational HR resources. As a result, these resources would leave. It would also be a mistake to employ operational HR resources for implementation when the involvement of line leaders and employees builds commitment to the goals of the intervention.

- Maintain business focus. In all considerations, operational HR must maintain an unrelenting focus on a business logic that is consistent with the logic of the corporate business portfolio. Regardless of whether the corporation is a single business unit, diversified, or a holding company, HR should maintain its focus on making the corporate business logic successful.

- Getting the structure right. Organizations are trying out different structures for operational HR. Sometimes they are a distinct unit (National City), other times they are distributed in embedded HR as junior professionals (Nestlé, Takeda Pharmaceutical Company) or in centers of expertise (Royal Bank of Scotland). Smart organizations have found ways to connect these resources to one another and provide common training and teambuilding experiences.

- Measuring contribution. Because operational HR is project- and implementation-oriented, how performance is meas- ured should also be project-based and implementation-based.

This operational executor role will continue to become clearer as HR professionals ensure that HR investments turn into capabilities that deliver on HR's vision and goals.

\section{Implications for HR Practice}

For HR to be a successful business within the business, it must have a clear strategy that delivers value. It must also have outcomes that focus on the organization's technical and organizational capability requirements. We also propose that it must have an organization that appropriately reflects the business model and business organization. In most cases, the HR organization will require responsibilities in five areas.

As HR leaders gain commitment to a value proposition for HR contribution, they often realize the need to reshape their organization to deliver value to their multiple stakeholders. While each HR reorganization is likely to contain unique dynamics, the following steps generally occur over a three- to five-year period:

As HR leaders gain

commitment to a

value proposition for

HR contribution,

they often realize

the need to reshape

their organization to

deliver value to their

multiple

stakeholders.

\section{Diagnose the business strategy} and organization. HR leaders need to make sure they understand the model of the business they support (holding company, allied/diversified, or single business). Also, HR leaders must understand how the business organization matches with its vision and strategy.

2. Align HR and business organization structures. Make sure you align your HR organization with your business organization. Do not fall prey to modern HR practices just because others are doing them.

3. Differentiate transaction and transformation work. Realize that both transaction and transformation work are important, but they are two different types of work. Ensure that you appreciate that these two 
types of work need to be managed differently. With transaction work, the goal is efficiency through standardization, automation, and consolidation. In contrast, transformation work has greater performance impact; is likely to be nonroutine; needs to be focused on stakeholder requirements; and should have the flexibility to meet and exceed all stakeholders' expectations.

4. Create a project team. Set up a project team that includes key stakeholders-line managers, HR pro-

\section{As HR departments}

organize resources

that align with

business strategy

and structure, value

will be created. fessionals from corporate, business unit, and specialist staffsplus external consultants, if needed, and charge it with creating the business case for HR transformation. Once that is done, the team needs to fully lay out the road map for transformation, define roles and responsibilities in the new organization, implement the project, and measure success.

5. Build transaction efficiencies. The options for transaction processing include service centers and call centers, technology that enables employees to do their own HR work, and outsourcing targeted or integrated HR actions to a third party.

6. Develop transformational effectiveness. Clearly define the roles and responsibilities for corporate, centers of expertise, embedded HR, and operational HR. Make sure that those who staff those roles have the competencies and commitment to do so.

7. Maintain balance. Work to maintain the optimal balance between corporate, functional, and business-unit demands. Drive business growth through strategic HR while efficiently delivering HR services. Encourage the development of HR knowledge and skill while meeting the mandate for business acumen on the part of HR professionals.

8. Monitor progress. Measures of success should include HR costs, which can be tracked from HR staff ratios and HR budgets. But measures of success should also include organization capabilities that are the outcomes of HR and track how HR delivers on its vision of adding value.

When these steps are followed, the HR department not only has strategies and goals that deliver value, but also an organization structure that reflects the business that it supports. As a result, the HR business within the business is positioned to deliver value.

\section{Implications for HR Research}

The ideas we have shared in this article reflect that state of practice in designing HR organization. But we also strongly believe that much additional research can and should be done to examine and refine these ideas. Some specific questions that merit research include:

- Under what business conditions do different ways of delivering HR impact on stakeholder performance (employees, customers, and investors)?

- What is the impact of alignment of the HR structure and business structure?

- Which HR structural configuration delivers the best organizational capability at the lowest cost?

- What are the competency requirements of HR professionals who work in each of the five roles and responsibilities?

- What are the ways that these five roles and responsibilities should interact with each other?

- Are there important differences in HR organization by industry? By company or broader national economic maturity? By geographic region?

- What are the important dimensions of change management in implementing this model? What seems to work best and when?

- How are structural solutions impacted by organizational differences in HR competence? What are the fundamental competence requirements? For HR organiza- 
tions with unusually high levels of professional competency, how is structure impacted?

- What variations in this form of structure seem to create the strongest business-HR partnership?

We are sure that these, and other, questions will help evolve the ever-changing role and responsibilities of the HR department.
As HR departments organize resources that align with business strategy and structure, value will be created.

\section{Acknowledgments}

Many of the ideas in this article were developed in The HR Value Proposition (Ulrich \& Brockbank, 2005). We appreciate comments from Dennis Shuler and Peter Reilly.

DAVE ULRICH is a professor of business at the Ross School of Business at the University of Michigan and a partner in the RBL Group. He has written a dozen books and more than 100 articles on how HR departments, practices, and professionals can deliver value. He has consulted with more than half of the Fortune 200 and worked to establish HR as a value-added profession.

JON YOUNGER is a partner in the RBL Group, a director of the RBL Institute, and leads the firm's strategic HR practice. He was previously chief talent and learning officer of $\mathrm{Na}$ tional City Corporation, a leading financial services organization. He has published in the Human Resource Management Journal, Human Resource Planning, the Harvard Business Review, and other publications, and is a coauthor with Professors Ulrich, Brockbank, and others of the HR Competencies: Mastery at the Intersection of People and Business (www.rbl.net). He consults widely with a broad range of leading companies. $\mathrm{His} \mathrm{PhD}$ is from the University of Toronto.

WAYNE BROCKBANK is a partner in the RBL Group and clinical professor of business at the Ross School of Business at the University of Michigan where he codirects the number-one-rated senior HR executive programs. His research and consulting focus on linkages between HR and business strategy and emerging high-value-added agendas of the HR profession. He has published widely in the Human Resource Management Journal, Human Resource Planning, and Personnel Administrator and is the coauthor with Dave Ulrich of The HR Value Proposition. He consults in his areas of expertise with major clients on every populated continent.

\section{NOTE}

1. We recognize that there are generally two types of "business strategy": (1) corporate strategy focuses more on the portfolio or mix of businesses and (2) business-unit strategy focuses on how a particular business unit anticipates and services customers to make money. Each view of strategy leads to business organization choices that then lead HR organization choices.

\section{REFERENCES}

Bergeron, B. (2003). Essentials of shared services. Hoboken, NJ: Wiley.
Brown, D., Caldwell, R., White, K., Atkinson, H., Tansley, T., Goodge, P., et al. (2004). Business partnering: A new direction for HR. London: CIPD.

Chartered Institute of Personnel and Development (CIPD). (2005). Why HR must seek to become a business partner. CIPD Impact Report. London: Author.

Christensen, R. (2005). Roadmap to strategic HR:Turning a great idea into a business reality. New York: AMACOM/American Management Association.

Cook, M. F. (1999). Outsourcing human resources functions. New York: AMACOM.

Deloitte Consulting. (2006). Global HR transformation. Retrieved July 31, 2008 from http://www.de- 
loitte.com/dtt/cda/doc/content/UK_C_GlobalHRTransformation.pdo

Herman Miller. (2007). About us. Retrieved May 25, 2007, from http://www.hermanmiller.com

Lawler, E. E., \& Galbraith, J. (1995). Organizing for the future: New approaches to managing complex organizations. San Francisco, CA: Jossey-Bass.

Lawler, E., Ulrich, D., Fitz-Enz, J., \& Madden, J. (2003). Human resources business process outsourcing: Transforming how HR gets its work done. San Francisco, CA: Jossey-Bass.

McRae, K. (2003). HR shared services-A growing trend. Human Resources. Retrieved June 11, 2004, from http://www.humanresourcesmagazine.com.au/ articles/8c/0c01a08c.asp

Mercer Human Resource Consulting. (2008). Retrieved January 23, 2008 from http://www.mercer.com/servicedetail.htm?idContent $=1287540 \&$ topicld $=140200076$

Reilly, P. (2000). HR shared services and the realignment of HR (IES Report 368). Brighton, UK: Institute for Employment Studies.
Reilly, P., Tamkin, P., \& Broughton, A. (2007). The changing HR function: A research into practice report. London: Chartered Institute of Personnel and Development.

Reilly, P., \& Williams, T. (2006). Strategic HR: Building the capability to deliver. London: Gower Publishing.

Scott-Jackson, W., Newham, T., \& Gurney, M. (2005). HR outsourcing: The key decisions (Executive briefing). London: Chartered Institute of Personnel and Development.

Ulrich, D. (1995). Shared services: From vogue to value. Human Resource Planning, 18(3), 12-22.

Ulrich, D., \& Brockbank, W. (2005). HR value proposition. Boston: Harvard Business Press.

Ulrich, D., Brockbank, W., Johnson, D., \& Younger, J. (2007). Human resource competencies: Responding to increased expectations. Employment Relations Today, 34(3), 1-12.

Ulrich, D., \& Smallwood, N. (2004, June). Capitalizing your capabilities. Harvard Business Review, pp. 119-127. 